Article

\title{
Upcycling Polymers and Natural Fibers Waste-Properties of a Potential Building Material
}

\author{
Sibele P. Cestari ${ }^{1, *}$, Luis C. Mendes ${ }^{1}$, Volker Altstädt ${ }^{2}$ and Léa M. A. Lopes ${ }^{1}$ \\ 1 Instituto de Macromoléculas Professora Eloisa Mano (IMA), Universidade Federal do Rio de Janeiro (UFRJ), \\ Avenida Horácio Macedo, 2030-Centro de Tecnologia, Bloco J, Cidade Universitária, \\ Rio de Janeiro 21941-598, Brazil; lcmendes@ima.ufrj.br (L.C.M.); llopes@ima.ufrj.br (L.M.A.L.) \\ 2 Lehrstuhl für Polymere Werkstoffe, Universität Bayreuth, FAN A, 2. Stock, Universitätsstraße 30, \\ Bayreuth 95447, Germany; altstaedt@uni-bayreuth.de \\ * Correspondence: scestari@ima.ufrj.br; Tel.: +55-21-3938-7227
}

Academic Editor: Michele Rosano

Received: 29 April 2016; Accepted: 17 June 2016; Published: 24 June 2016

\begin{abstract}
Composites of recycled high-density polyethylene and micro fibres of sugarcane bagasse were studied, in order to create an upcycled material to produce masonry bricks. We ranged the polymer/filler ratio from $100-0$ to $60 \%-40 \%$. The materials were assessed through scanning electron microscopy, thermogravimetry/derivative thermogravimetry, differential scanning calorimetry, rheological measurements and compressive strength test. The composites showed a good dispersion and adhesion of the filler into the polymeric matrix. There was no significant variation on the melting and crystallizing temperatures of the materials if compared to those of neat polymer, indicating that there was no relevant change in the average size of the polymeric crystals. We assumed that some transcrystallization has happened, because the degree of crystallinity of the composites increased to all filler contents, while the crystallizing temperature remained the same. There was a rise in the compressive moduli of the composites, ranging from $37 \%$ to $63 \%$. The modulus at the crossover point and the complex viscosity also rose due to the fibres ratio. The results show that the combination of these materials led to the reinforcement of the compressive strength of the polymer, and have interesting properties as a potential building material.
\end{abstract}

Keywords: polymer composite; high-density polyethylene; compressive strength; rheology; recycling; sustainability

\section{Introduction}

The search for sustainable solutions is visible in all sectors of human activity [1,2]. It is increasingly recurrent for contemporary society to consider environmental issues in the developments in science and technology. The concern about the preservation of natural resources-as a consequence of the awareness of its finitude-makes itself present in several fields of academic research. Studies lead to new polymeric materials, which can provide a sustainable destination for synthetic waste with which nature cannot address [3-6]. Transforming large scale waste into a commodity product would deal with both environmental and economic issues [7,8]. In addition, upcycling materials can be more sustainable than recycling them $[9,10]$. The construction industry is the second largest market of polymers as raw material [11]. The numbers point out that $40 \%-75 \%$ of natural resources and $40 \%-44 \%$ of the energy produced on the planet are consumed by this activity [12-14]. This could be an interesting field to develop solutions using recycled polymeric materials, as Conroy and co-workers noticed in 2006 [15].

Regarding the Brazilian market, high density polyethylene (HDPE) is one of the most widely used polyolefins, and represents the biggest volume (37\%) of urban plastic waste [16]. In addition, sugarcane 
bagasse (SCB) is one of the many natural fibres considered a large-scale waste; $90 \%$ of this material is used in very primary ways (livestock feed, or fuel for thermoelectric generators). If ever used as input for a building material, this same fibre would gain more valuable applications. In a former work, our research group tried to develop a synthetic paper, using virgin HDPE and SCB [17]. By that time, we noticed the high compressive resistance of those composites. Later, we developed another material using a different fibre (which resulted in inert filler) [18-20]. From this point of view arose the idea of using recycled HDPE (rHDPE) and SCB to create a reinforced material for the construction industry. The choice for recycled HDPE led us to find in literature other interesting information about the use of this polyolefin as building material-more specifically, as a material resisting to compressive strength. As stated by Bozorg-Haddad and co-workers when studying compressive strength and creep of polymeric piling made of recycled HDPE [21], in compressive loading, the cross-section of polymeric materials increases; consequently, the stress tends to decrease. Even if not used for structural purposes, a brick made of this polymer (HDPE with SCB) would tend to become tougher over time. This improvement on the mechanical properties of the brick would be obtained just due to the nature of the creep behaviour of HDPE, without further chemical or physical treatments in the polymer. Therefore, the aim of this work was to assess the feasibility of using rHDPE/SCB composites as material for masonry bricks.

\section{Materials and Methods}

\subsection{Materials}

The materials used were recycled HDPE (rHDPE), in the shape of pellets, having a density of 0.973 , and melt flow rate (MFR) of $2.589 \pm 0.209 \mathrm{~g} \cdot 10 \mathrm{~min}^{-1}$, donated by the COMBRARE recycler (Manufacturer, City, Country); the sugarcane bagasse (SCB) was donated by HC Sucroquímica sugarcane plant (Campos dos Goytacazes, Rio de Janeiro, Brazil). The latter was used without any previous chemical treatment and then grinded and sifted using a sieve with 32 mesh, according to the ASTM C136 [20]. The SCB micro fibre that passed through the sieve was used in the composites. Before processing, both materials were dried overnight in a vacuum oven at $80^{\circ} \mathrm{C}$.

\subsection{Composite and Specimen Preparation}

Four composites were prepared (100-0, 80-20, 70-30 and 60-40), the filler ratio ranging from 0 to $40 \%$. The materials were dried overnight in a vacuum oven at $80{ }^{\circ} \mathrm{C}$, and then compounded in a Teck Tril ${ }^{\circledR}$ co-rotating twin-screw extruder (Length/Diameter ratio of the screw $=36$, screw diameter $=22 \mathrm{~mm}$ ), equipped with a vacuum system, model DCT-20. The processing parameters were: temperature profile of 70,100, 150, 160, 170, 180, 190, 200 and $200{ }^{\circ} \mathrm{C}$; die temperature of $200{ }^{\circ} \mathrm{C}$; extrusion speed of $300 \mathrm{rpm}$; feeder speed of $20 \mathrm{rpm}$. The thermogravimetry/derivative thermogravimetry and differential scanning calorimetry analysis were performed over grinded pellets. Scanning electron microscopy was performed over laminates, obtained by compression moulding in a heated press at $200{ }^{\circ} \mathrm{C}$, and $3 \mathrm{MPa}$, for $5 \mathrm{~min}$, and then cooled down in a press at $25^{\circ} \mathrm{C}$, and $3 \mathrm{MPa}$, for $5 \mathrm{~min}$. The specimens for compressive resistance test were injection moulded into cylinders of $20 \mathrm{~mm}$ height and $10 \mathrm{~mm}$ diameter, using an Arburg ${ }^{\circledR}$ All Rounder 420C 800-250 equipment (City, Country). The processing parameters were: temperature profile of 185/185/185/185 and 185 (nozzle) ${ }^{\circ} \mathrm{C}$; clamping force of $80 \mathrm{kN}$; holding pressure of $200 \mathrm{MPa}$, mound temperature of $105^{\circ} \mathrm{C}$; holding pressure time of $12 \mathrm{~s}$; closed mound time of $30 \mathrm{~s}$; and injection cycle time of $50 \mathrm{~s}$. The molten material was injected using $245 \mathrm{MPa}$ pressure, and speed of $0.7 \mathrm{~cm}^{3} \cdot \mathrm{s}^{-1}$. Injection branches of cylinders were removed using a $\mathrm{EMCO}^{\circledR}$ Maximat V13 lathe. 


\subsection{Methods}

\subsubsection{Scanning Electron Microscopy (SEM)}

The SEM analysis was performed using an Fei Company microscope model Quanta 200, over specimens coated with $300 \mathrm{~nm}$ gold particles (Au) applied by a Quorum equipment model Q150R ES, metallization time $120 \mathrm{~s}$, using $27 \mathrm{~mA}$. Cryogenically fractured transversal sections of the samples were assessed.

\subsubsection{Thermogravimetry/Derivative Thermogravimetry (TG/DTG)}

The TG/DTG analysis was performed using TA equipment model Q500. The temperature range was from 30 to $700{ }^{\circ} \mathrm{C}$, at heating rate of $10^{\circ} \mathrm{C} \cdot \mathrm{min}^{-1}$, under nitrogen atmosphere. We measured the mass loss, initial $\left(\mathrm{T}_{\text {onset }}\right)$, maximum speed $\left(\mathrm{T}_{\max }\right)$ and final $\left(\mathrm{T}_{\text {final }}\right)$ degradation temperatures.

\subsubsection{Differential Scanning Calorimetry (DSC)}

The DSC analysis was performed using TA equipment Q1000 model. The samples were analysed under nitrogen atmosphere, according to the following cycles: in the first cycle, the sample was heated from 20 to $200^{\circ} \mathrm{C}$, at a heating rate of $10^{\circ} \mathrm{C} \cdot \mathrm{min}^{-1}$, keeping the material at $200{ }^{\circ} \mathrm{C}$ for $1 \mathrm{~min}$; the second cycle was done using a cooling rate of $10{ }^{\circ} \mathrm{C} \cdot \mathrm{min}^{-1}$, until $20{ }^{\circ} \mathrm{C}$; at the third cycle, the same temperature range and heating rate of the first cycle were applied. The cooling crystallization temperature $\left(\mathrm{T}_{\mathrm{c}}\right)$ was obtained considering the cooling curve. The crystalline melting temperature $\left(\mathrm{T}_{\mathrm{m}}\right)$ and the degree of crystallinity $\left(X_{c}\right)$ of the HDPE were obtained considering the second heating curves. The $X_{c}$ was determined based on the ratio between the melting enthalpy $\left(\Delta H_{m}\right)$ of the HDPE in the composite and the $100 \%$ crystalline HDPE $\left(290 \mathrm{~J} \cdot \mathrm{g}^{-1}\right)$, adjusted according to the content of polyolefin in the composite.

\subsubsection{Compressive Strength}

Compressive strength test was performed according to ASTM D 695 [22], in a Zwick universal tester 1485 model, using a $250 \mathrm{kN}$ load cell, test speed of $1.3 \mathrm{~mm} \cdot \mathrm{min}^{-1}$, until $20 \%$ deformation. This test was held at New Materials Centre of Bayreuth, at Bayreuth, Germany.

\subsubsection{Rheological Measurements}

The rheological measurements were performed in the molten state, in a parallel plate rheometer (diameter $25 \mathrm{~mm}$, gap $1 \mathrm{~mm})$ TA Instruments, model AR 2000, in oscillatory shear mode $\left(200{ }^{\circ} \mathrm{C}, \mathrm{N} 2\right.$ atmosphere). Tests of deformation variation were made to obtain the linear viscoelastic region, at the angular frequency $(\omega)$ of $6.28 \mathrm{rad} \cdot \mathrm{s}^{-1}$. The storage $\left(\mathrm{G}^{\prime}\right)$ and loss $\left(\mathrm{G}^{\prime \prime}\right)$ moduli and the complex viscosity $\left(\eta^{*}\right)$ were determined considering the linear viscoelastic region of the material, in the frequency range between 0.6 and $500 \mathrm{rad} \cdot \mathrm{s}^{-1}$.

\section{Results and Discussion}

The SEM images of the composites (Figure 1) showed a fine dispersion between polymer and filler. We saw the same good dispersion between HDPE and SCB in a former work [17]; we ascribed it to the very fine fibres - which passed through the \#100 mesh sieve-equivalent to 55\% of the total SCB used in the composites. The images showed that most of the SCB particles were fractured instead of pulled (Figure 2). This can be taken as an indication of good adhesion between the materials. We believe that the presence of lignin in the SCB acted as coupling agent between polymer and filler $[23,24]$. Considering that we did not use any delignification process ( $\mathrm{NaOh}, \mathrm{H} 2 \mathrm{SO} 4)$ or compatibilizing agent-as is usual in natural fibre reinforced composites (NFRC) literature-the interface resulted adequately for the intended purpose. The SEM images on Figures 1 and 2 show broken fibres in the cryogenically fractured section, denoting a strong polymer/filler interaction. The increase in the filler 
content tends to decrease the adhesion-shown by some voids in the polymeric matrix in Figure 1c. Most of them were caused by pulled fibres that were positioned parallel to the fracture section. As the intended application is compressive stress, this pulling effect on the SCB fibres will not be a problem.

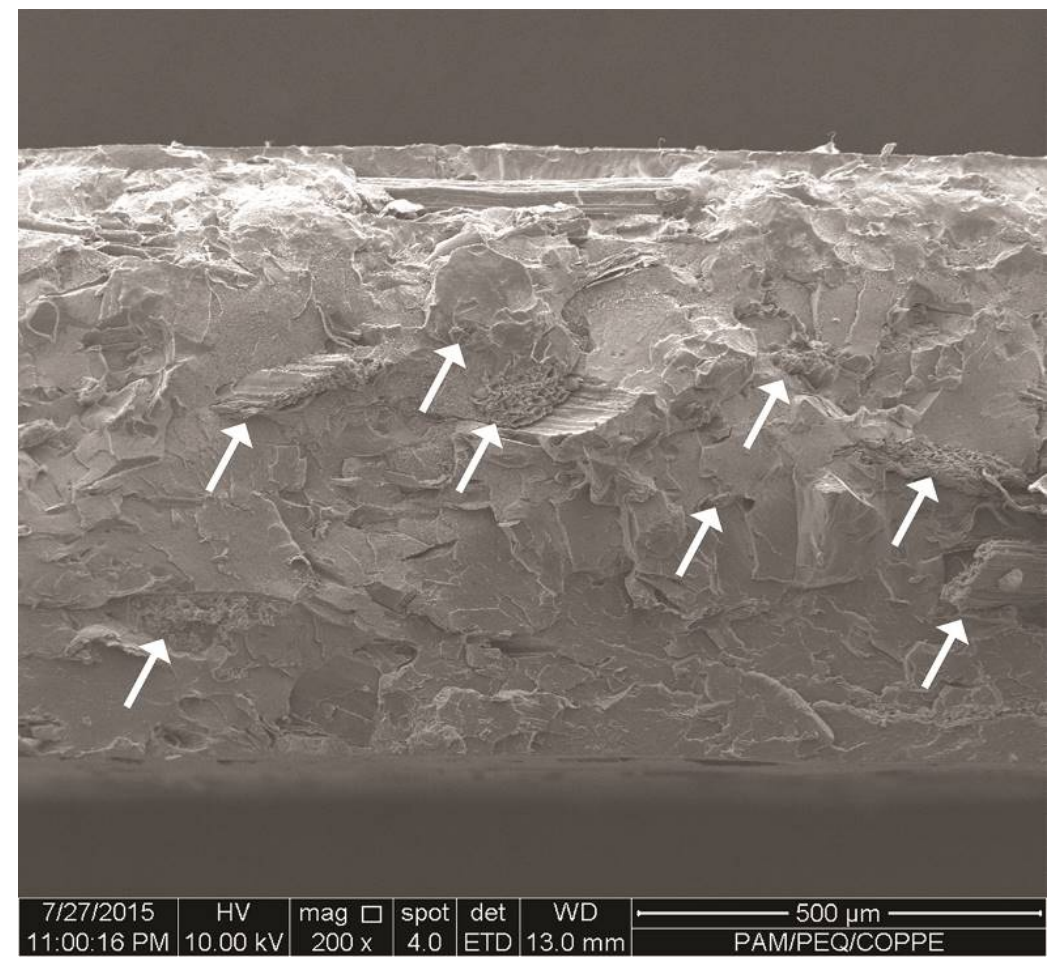

(a)

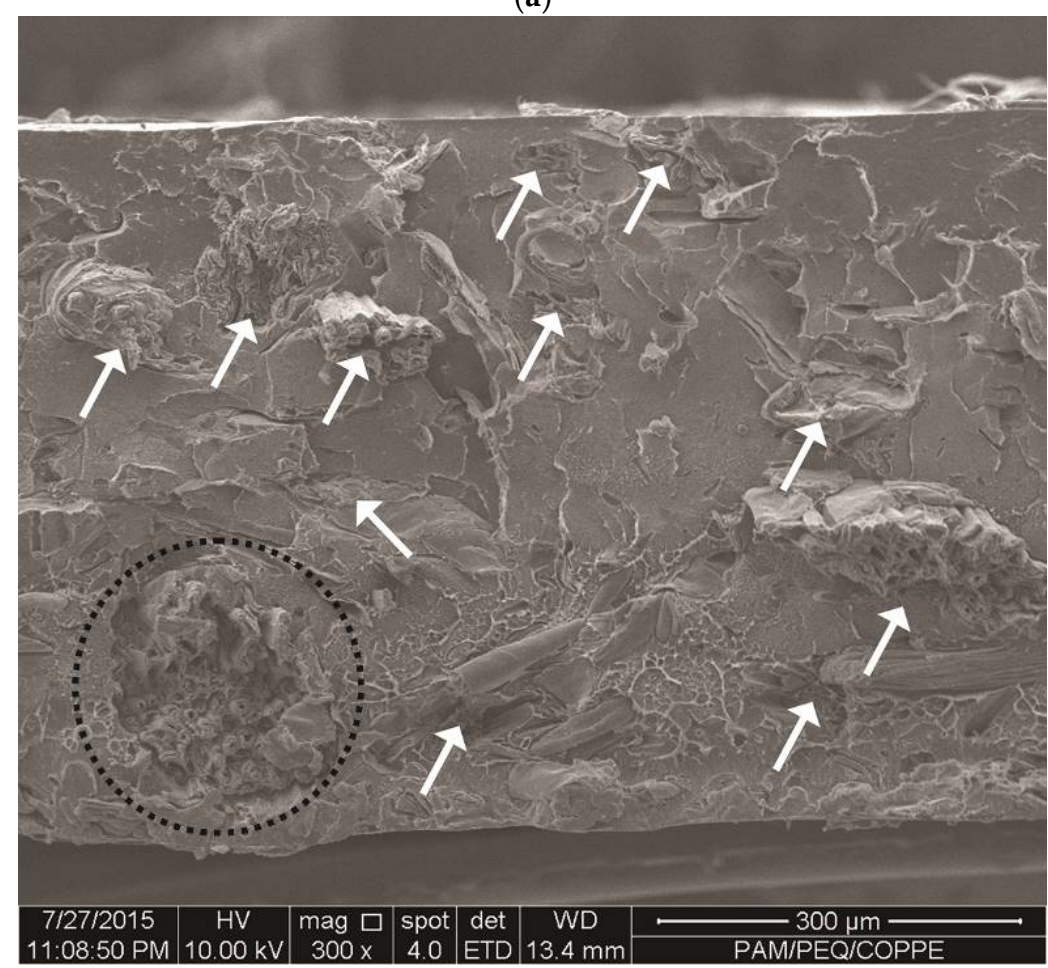

(b)

Figure 1. Cont. 


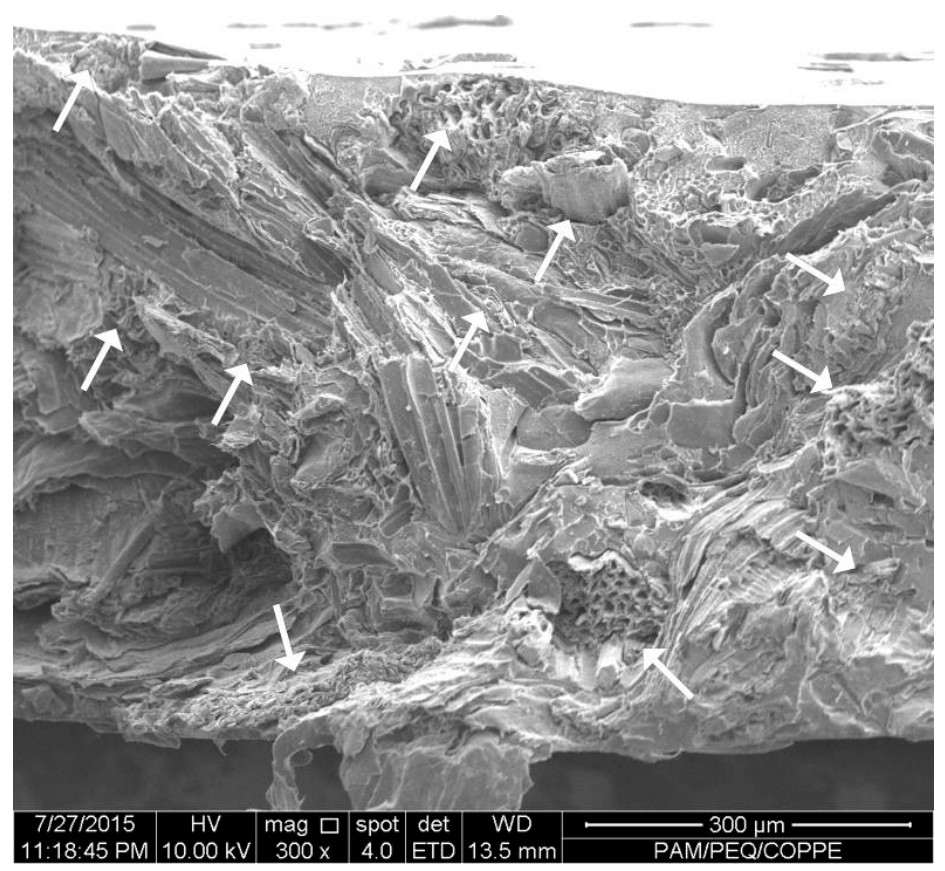

(c)

Figure 1. Scanning Electron Microscopy photomicrographies of the composites 80-20 (a), 70-30 (b), and $60-40(\mathbf{c})$, magnified $300 \times$.

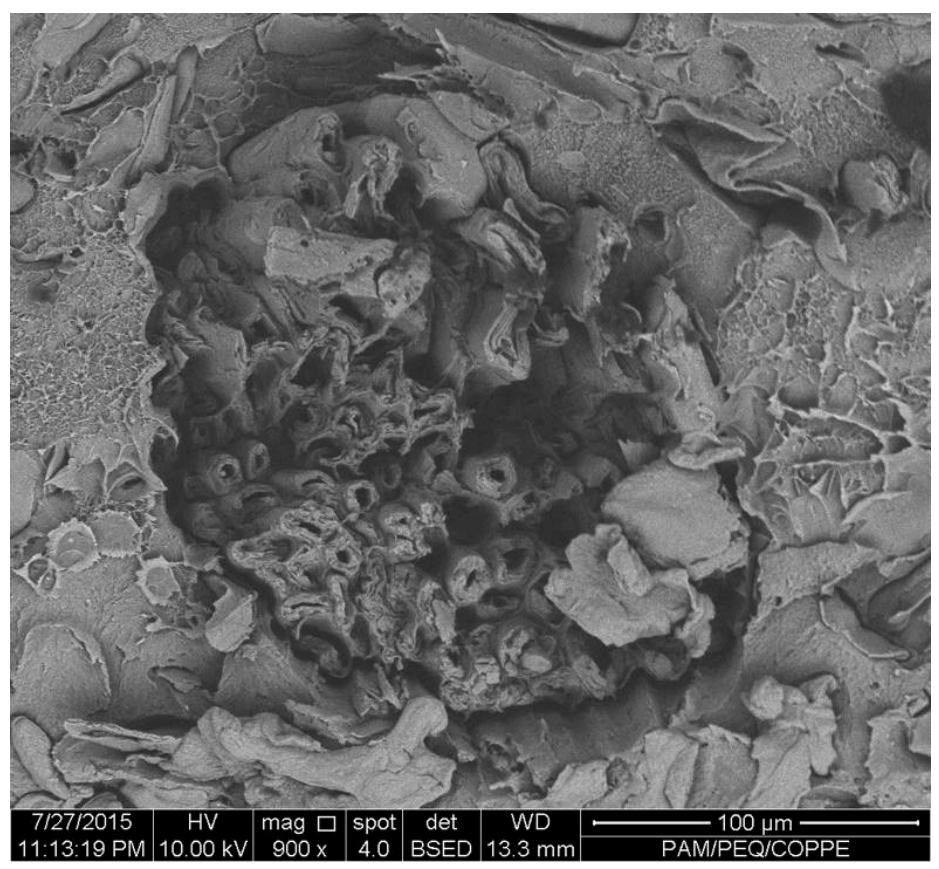

Figure 2. SEM photomicrographies- $900 \times$ magnification of the dashed circle in Figure $1 \mathrm{~b}$ (composite 70-30).

Figures 3 and 4 and Table 1 show the $\mathrm{T}_{\text {onset, }} \mathrm{T}_{\text {final }}, \mathrm{T}_{\max }$ and the residue content of the composites. As expected, the 100-0 composite showed single-step degradation, leaving 1\% residue. The rest of the materials showed three different steps of mass loss due to the presence of SCB, as seen in a former work [17]. According to literature, the composition of sugarcane bagasse is mainly cellulose (50\%), hemicellulose (25\%) and lignin (25\%) [25,26]. The first step of mass loss-until $295^{\circ} \mathrm{C}-$ was ascribed to 
the hemicellulose present in the fibres. The second step $\left(295-380^{\circ} \mathrm{C}\right)$ was probably linked to cellulose mass loss. In addition, the third step was ascribed to the degradation of lignin; this last step caused a slight decrease $(2 \%)$ in the $\mathrm{T}_{\text {onset }}$ of the rHDPE. These steps were better seen through the changes in the DTG curves, where the $\mathrm{T}_{\max }$ peaks usually show up. The first one was noticed by a slight "shoulder" - around $290^{\circ} \mathrm{C}$ - which became more well defined as the filler content increased; the second one was around $347^{\circ} \mathrm{C}$, and also became sharper with more SCB in the composite. Despite the general decrease in the $\mathrm{T}_{\text {onset }}$ of the neat rHDPE, the materials started to lose mass after the average processing temperature of $\mathrm{HDPE}$ (around $200^{\circ} \mathrm{C}$ ).

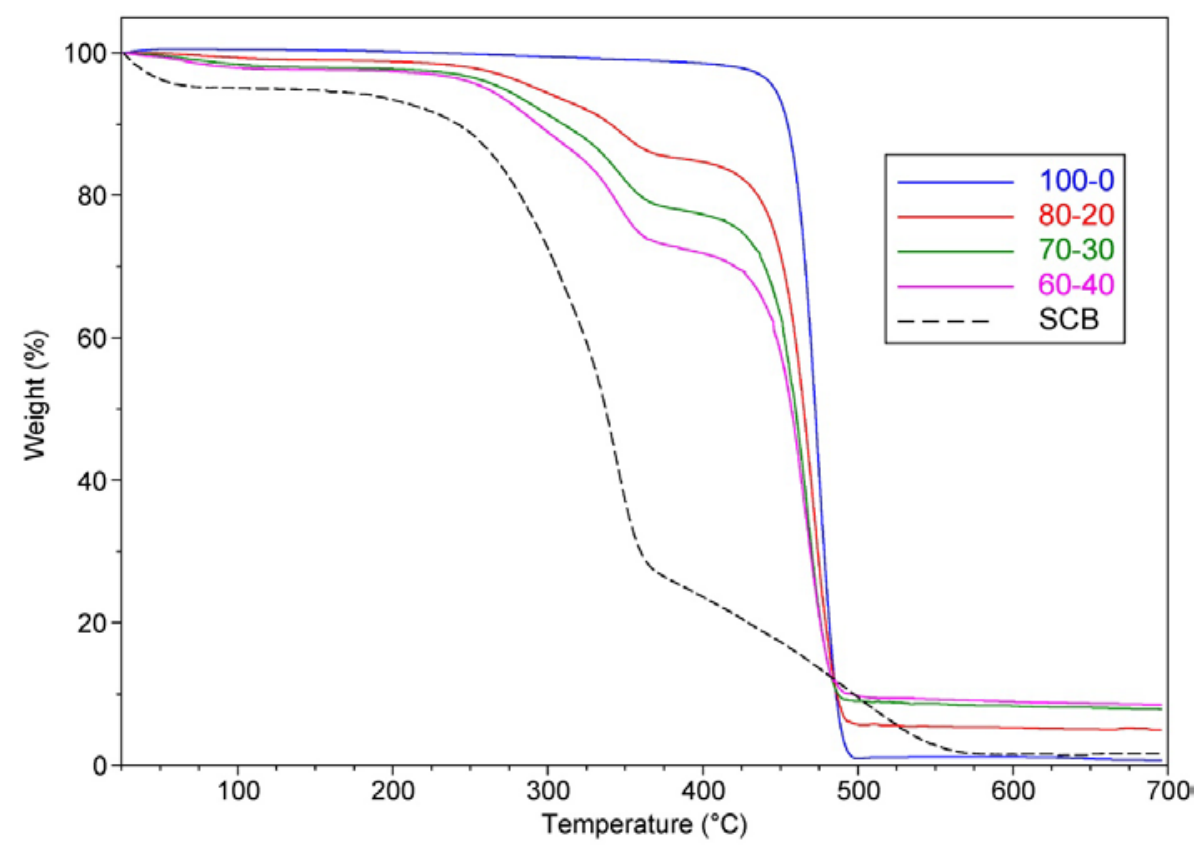

Figure 3. Superimposition of the Thermogravimetric curves of the materials.

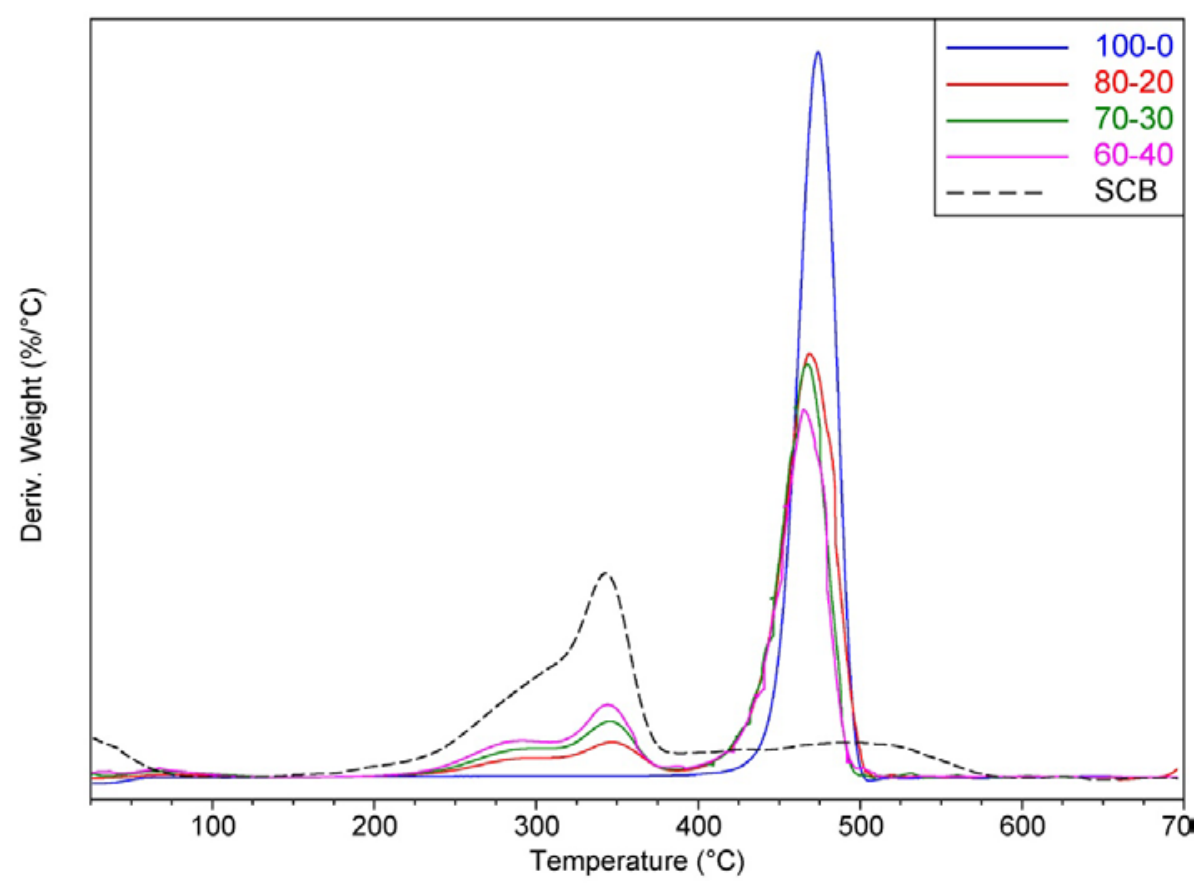

Figure 4. Superimposition of the Derivative Thermogravimetric curves of the materials. 
Table 1. Thermogravimetric/Derivative Thermogravimetric data of the composites.

\begin{tabular}{ccccc}
\hline Material & $\mathbf{T}_{\text {onset }}\left({ }^{\circ} \mathbf{C}\right)$ & $\mathbf{T}_{\text {final }}\left({ }^{\circ} \mathbf{C}\right)$ & $\mathbf{T}_{\max }\left({ }^{\circ} \mathbf{C}\right)$ & Residue (\%) \\
\hline $100-0$ & 459 & 500 & 475 & 1 \\
$80-20$ & $299 / 451$ & 500 & $348 / 471$ & 5 \\
$70-30$ & $256 / 332 / 449$ & 500 & $347 / 467$ & 8 \\
$60-40$ & $254 / 333 / 448$ & 500 & $291 / 346 / 468$ & 9 \\
\hline
\end{tabular}

Figure 5a-d shows the DSC curves of the materials. Considering the second heating cycle (Table 2 and Figure 6), there was no significant variation in the $T_{m}$ and the $T_{c}$ of the rHDPE in the composites (133 and $120^{\circ} \mathrm{C}$, respectively). This could mean that there was no change in the average size of the crystals of the polymer. The $X_{c}$ increased non-linearly, raising $18 \%$ in the $80-20$ composite, $11 \%$ in the $70-30$ and $20 \%$ in the $60-40$. The anomalous behaviour of 70-30 can be explained as a consequence of the very small mass of the tested sample in this kind of analysis ( 5 to $7 \mathrm{mg}$ ). There is also the fact that polymeric composites filled with natural fibres are not homogeneous materials; despite of the efficiency of the compounding process, each separate small portion of the material does not have the exact polymer/filler ratio desired.

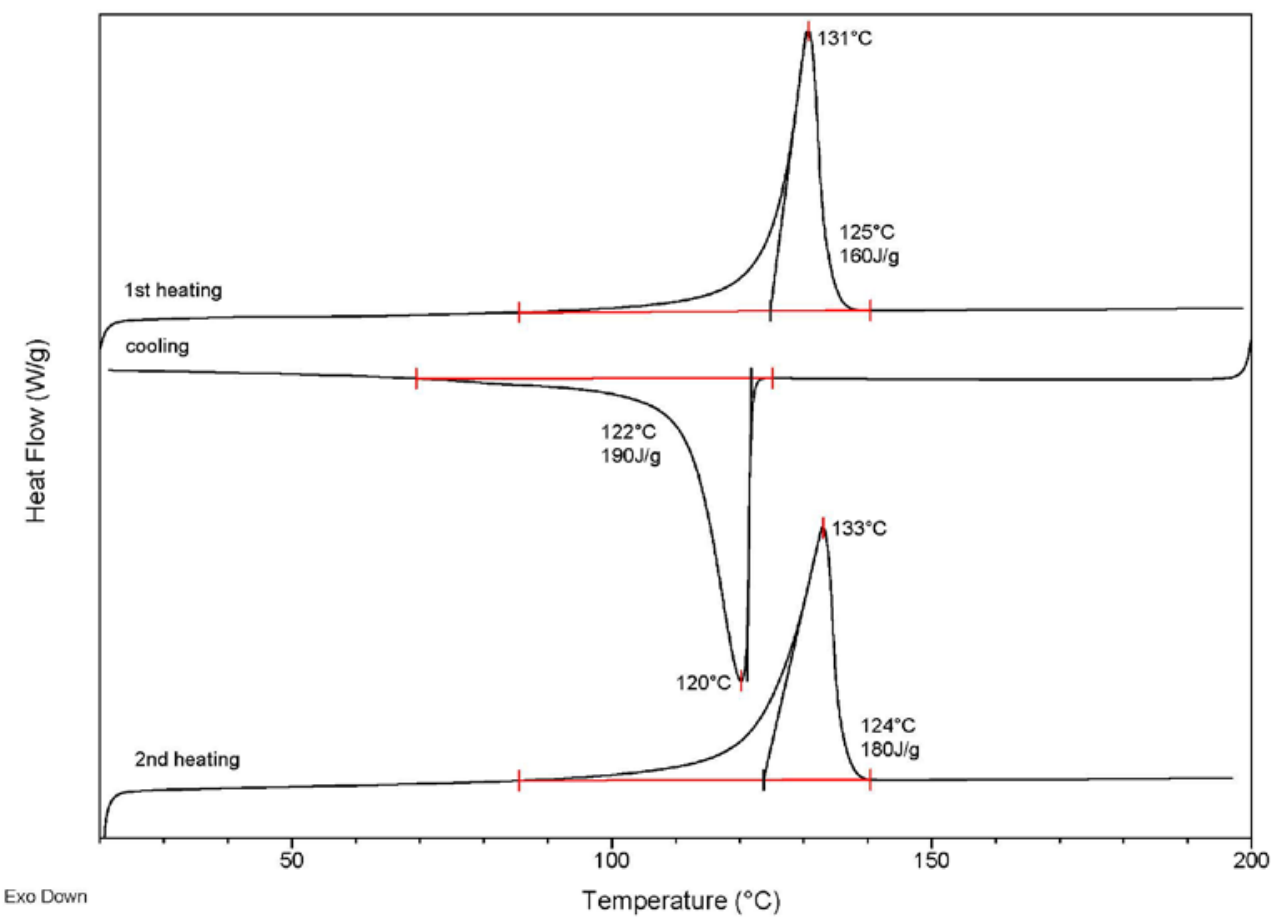

(a)

Figure 5. Cont. 


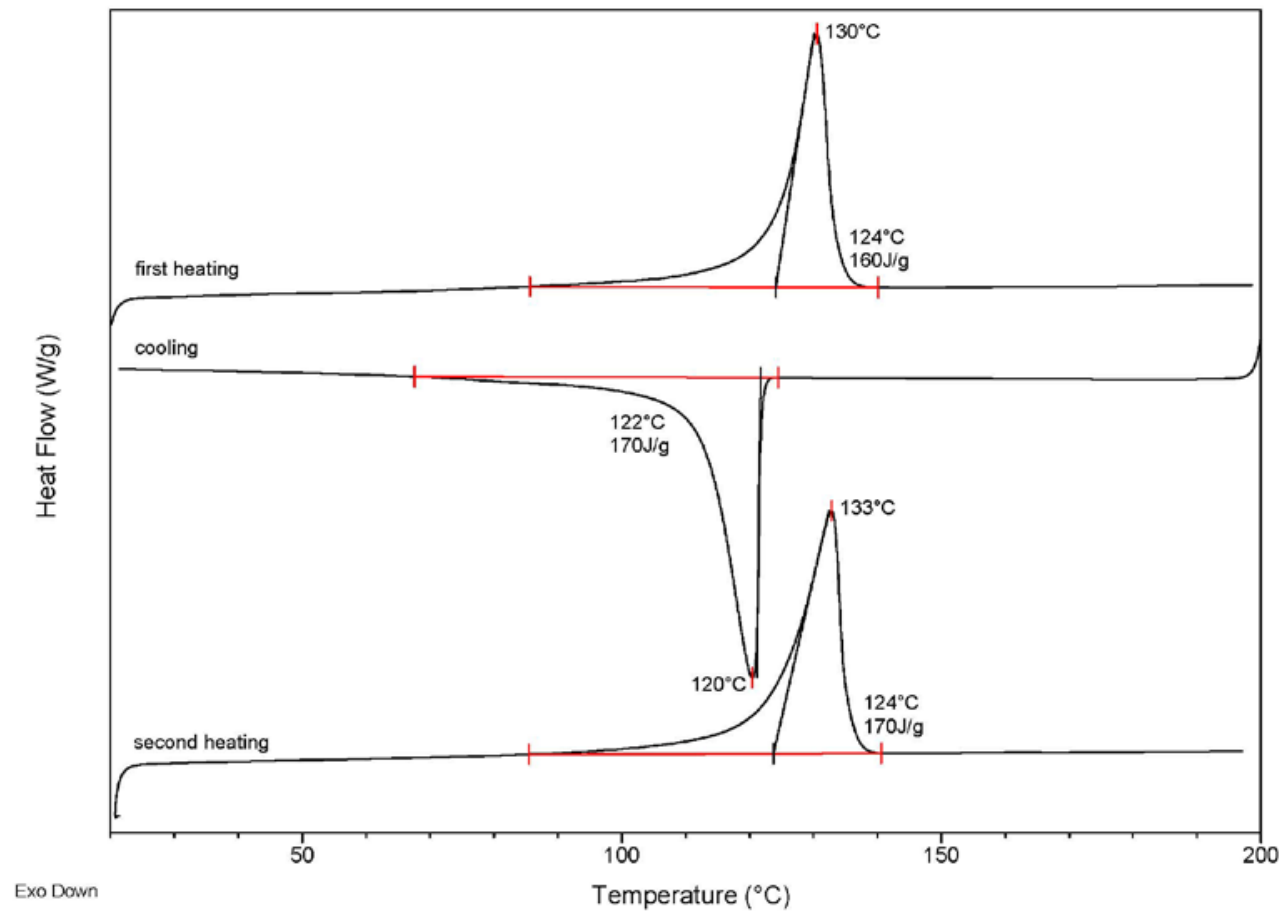

(b)

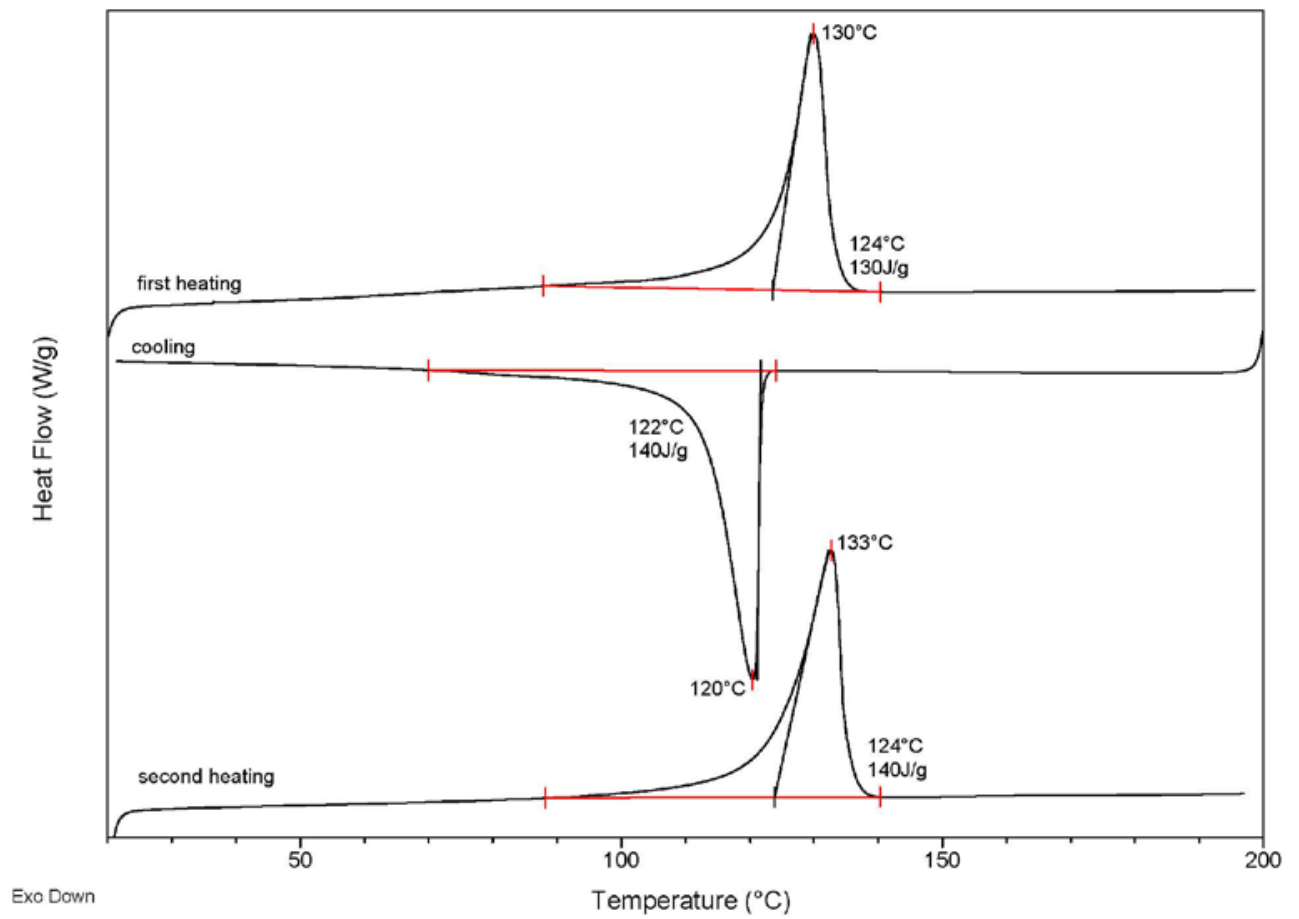

(c)

Figure 5. Cont. 


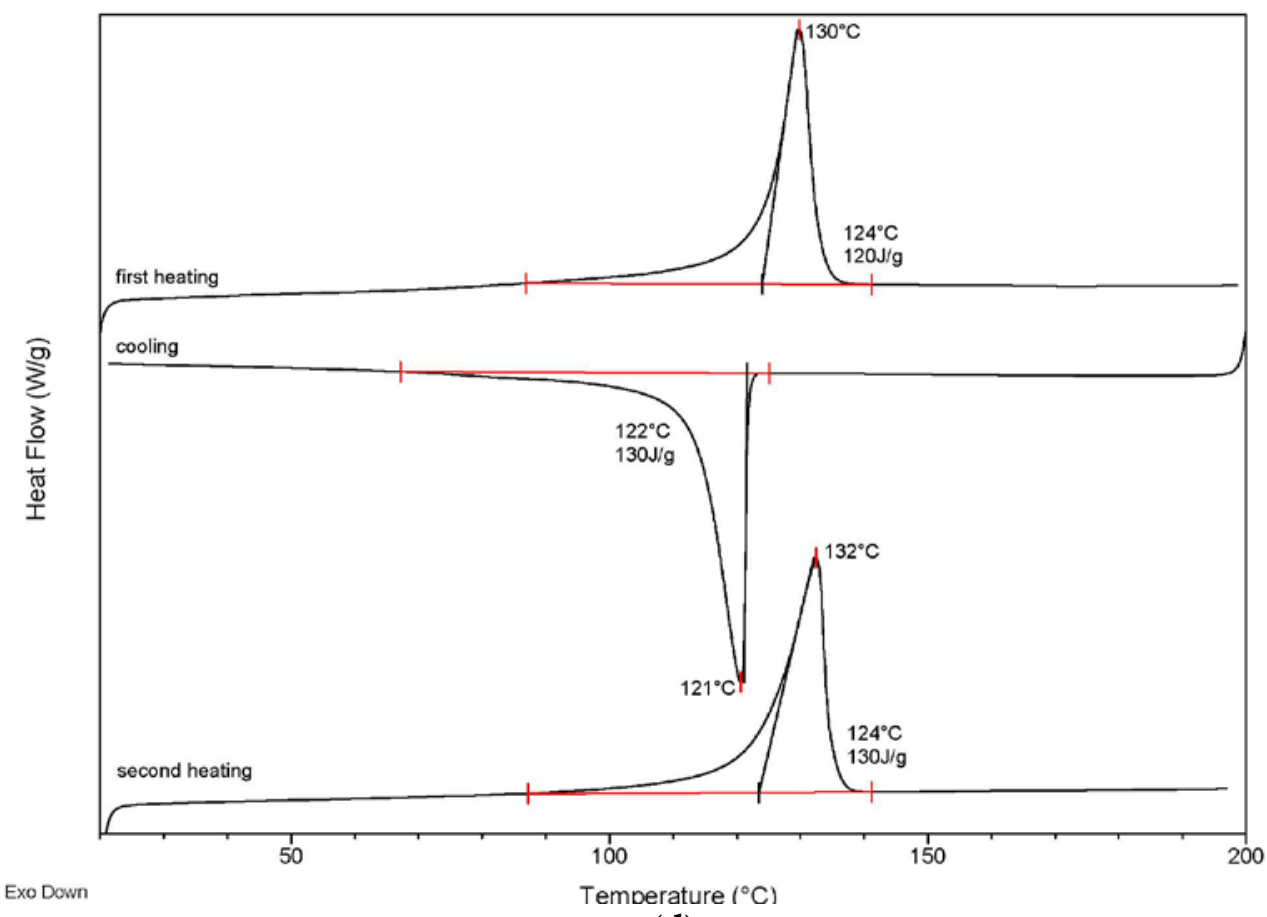

(d)

Figure 5. Differential Scanning Calorimetry curves of the 100-0 (a), 80-20 (b), 70-30 (c), and 60-40 (d) composites.

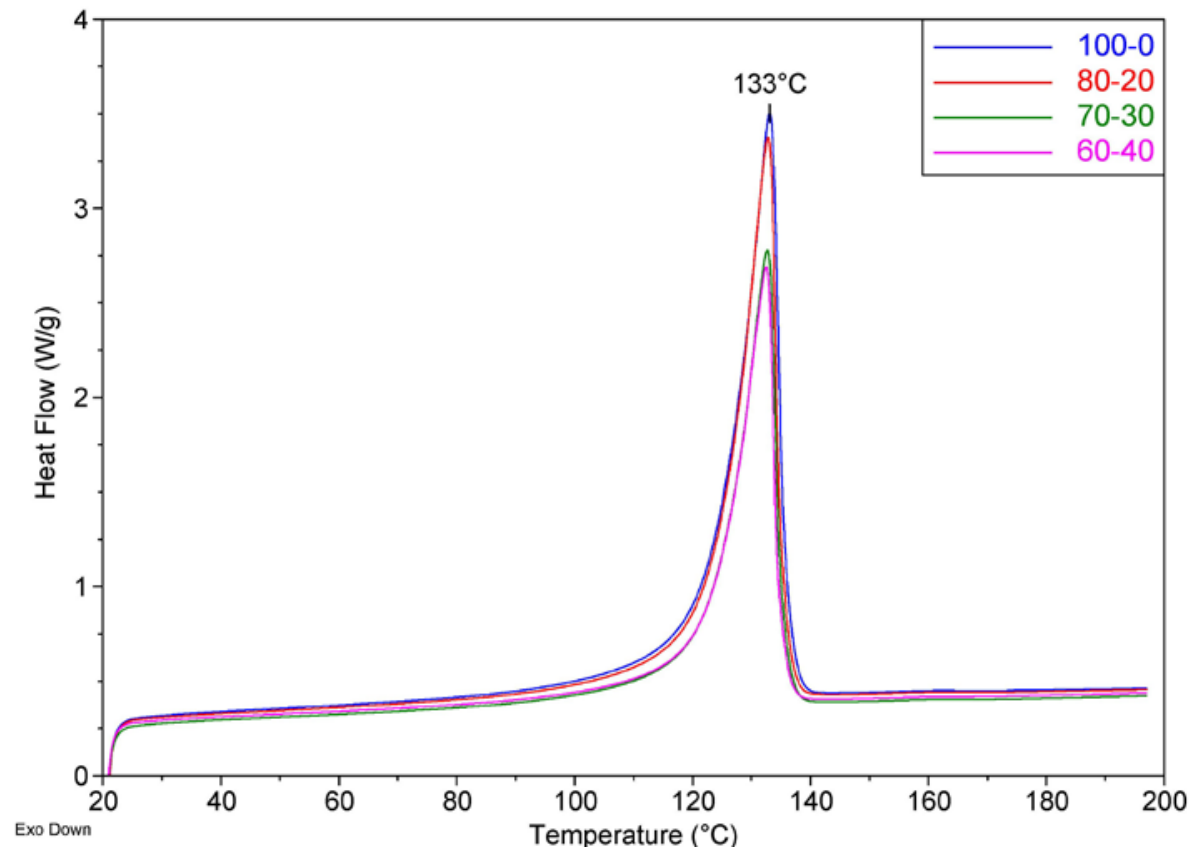

Figure 6. Superimposition of the DSC curves-2nd heating cycle. 
Table 2. Differential Scanning Calorimetry data of the composites.

\begin{tabular}{ccccc}
\hline Material & $\mathbf{T}_{\mathbf{m}}\left({ }^{\circ} \mathbf{C}\right)$ & $\Delta \mathbf{H}_{\mathbf{m}}\left({ }^{\circ} \mathbf{C}\right)$ & $\mathbf{T}_{\mathbf{c}}\left({ }^{\circ} \mathbf{C}\right)$ & $\mathbf{X}_{\mathbf{c}}(\mathbf{\%})$ \\
\hline $100-0$ & 133 & 180 & 120 & 62 \\
$80-20$ & 133 & 170 & 120 & 73 \\
$70-30$ & 133 & 140 & 120 & 69 \\
$60-40$ & 132 & 130 & 121 & 75 \\
\hline
\end{tabular}

The $\Delta \mathrm{H}_{\mathrm{m}}$ decreased according to the filler content, showing a progressive interference of the filler in the crystalline packing of the polymer. As seen in former works $[17,27]$, we assume that some transcrystallization has happened because the $X_{c}$ raised, while the $T_{c}$ remained the same. This phenomenon happens under homogeneous nucleation, and in composites can be considered a separate case of crystallization (heterogeneous nucleation induced by the fibre surface) $[28,29]$. The increase in the $X_{c}$ of the polymer is probably related to the transcrystallization furthered by the SCB over regions of uncrystallized polymer in the matrix.

According to ASTM D695-Standard Test Method for Compressive Properties of Rigid Plastics [22], section A1.3: "In the case of a material that does not exhibit any linear region ( ... ), any attempt to use the tangent through the inflection point as a basis for determination of an offset yield point may result in unacceptable error"(page 6). As the compressive strength curves of our materials did not exhibit any linear region (Figure 7), we calculated the secant compressive moduli ( $\mathrm{E}_{\mathrm{cs}}$ ) of each composite (Table 3). The results were calculated using the median curve of seven tested specimens because, this way, we obtained the moduli directly from an actual experimental curve-instead of plotting a theoretical curve and applying the standard deviation of the seven specimens over it. With $20 \%$ of SCB, the $\mathrm{E}_{\mathrm{CS}}$ of the polymer increased $46 \%$, raised a little less (37\%) with $30 \%$ SCB and reached $63 \%$ of increase with $40 \%$ SCB. According to the Brazilian standard for masonry bricks [30], the values of $\mathrm{E}_{\mathrm{cs}}$ for all materials (between 5 and $15 \mathrm{MPa}$ ) were enough to make closing wall (non-structural) bricks.

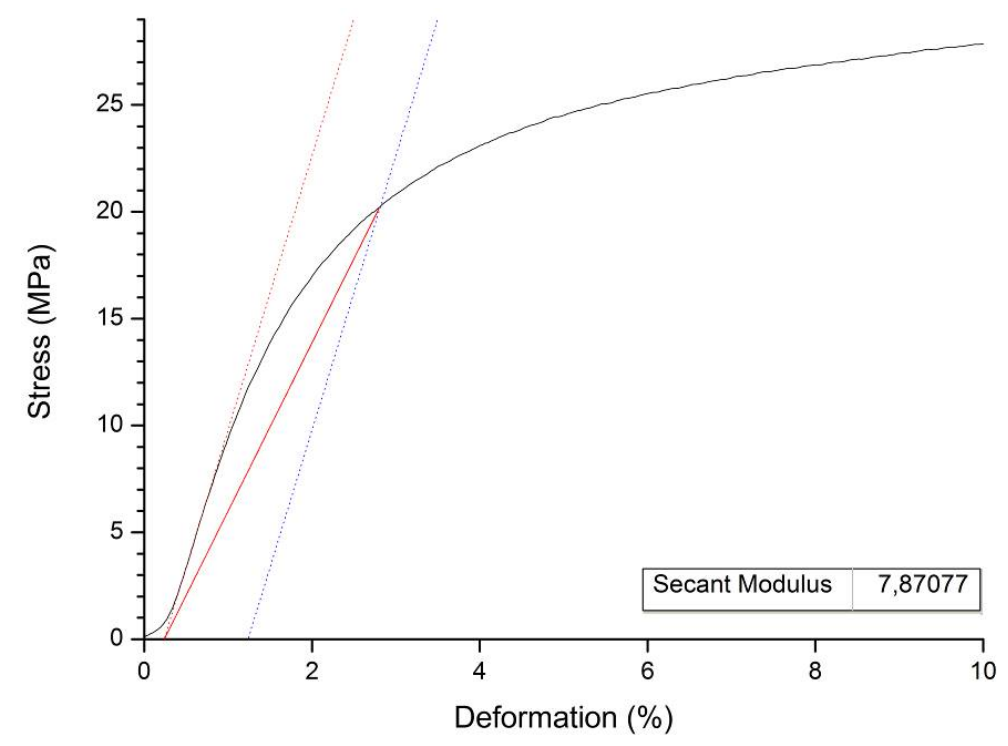

Figure 7. Secant modulus of the composites 80-20. 
Table 3. Secant compressive modulus $\left(\mathrm{E}_{\mathrm{cs}}\right)$ of the materials.

\begin{tabular}{cc}
\hline Composite & $\mathrm{E}_{\mathbf{c s}}(\mathbf{M P a})$ \\
\hline $100-0$ & 5.39 \\
$80-20$ & 7.87 \\
$70-30$ & 7.36 \\
$60-40$ & 8.80 \\
\hline
\end{tabular}

In the rheological measurements, we initially performed the deformation variation tests of the composites, in order to determine the strain interval of the linear viscoelasticity. The superimposition of the moduli versus deformation curves showed that, for all composites, the $1 \%$ strain was inside the linear viscoelastic plateau. Then, we made the frequency variation $(f v)$ tests for all materials. The data obtained-angular frequency and module at the crossover point-are shown in Figure 8. The composites showed an increase in the modulus at the crossover point, showing that the presence of SCB in the polymeric matrix has raised the resistance to deformation of the rHDPE. The crossover point-point where the values of elastic and viscous contributions of the material are equal—can show variations in the molecular weight and molecular weight distribution of polymers; and may be used as an indication of the relaxation time of a material. We can make an analogy between the changes in the crossover point of a neat polymer and composites of the same polymer, in an attempt to understand variations of the melt flow behaviour of the materials [31]. The values of $G^{\prime}$ and $G^{\prime \prime}$ at the crossover point were shifted left and up, increasing 34\% (80-20), 91\% (70-30) and 240\% (60-40). Compared to the neat polymer, this change to the left can be interpreted as an increase in the hydrodynamic volume of the SCB particles covered by the polymer. In addition, the variation to higher values could mean the raise in the homogeneity of the material as a whole (rHDPE+SCB), as well as more homogeneity in the SCB fibres. The shearing that occurred in the material may have furthered this improvement on the uniformity of the composites, especially on the 60-40 one-where the modulus at the crossover point raised $240 \%$.

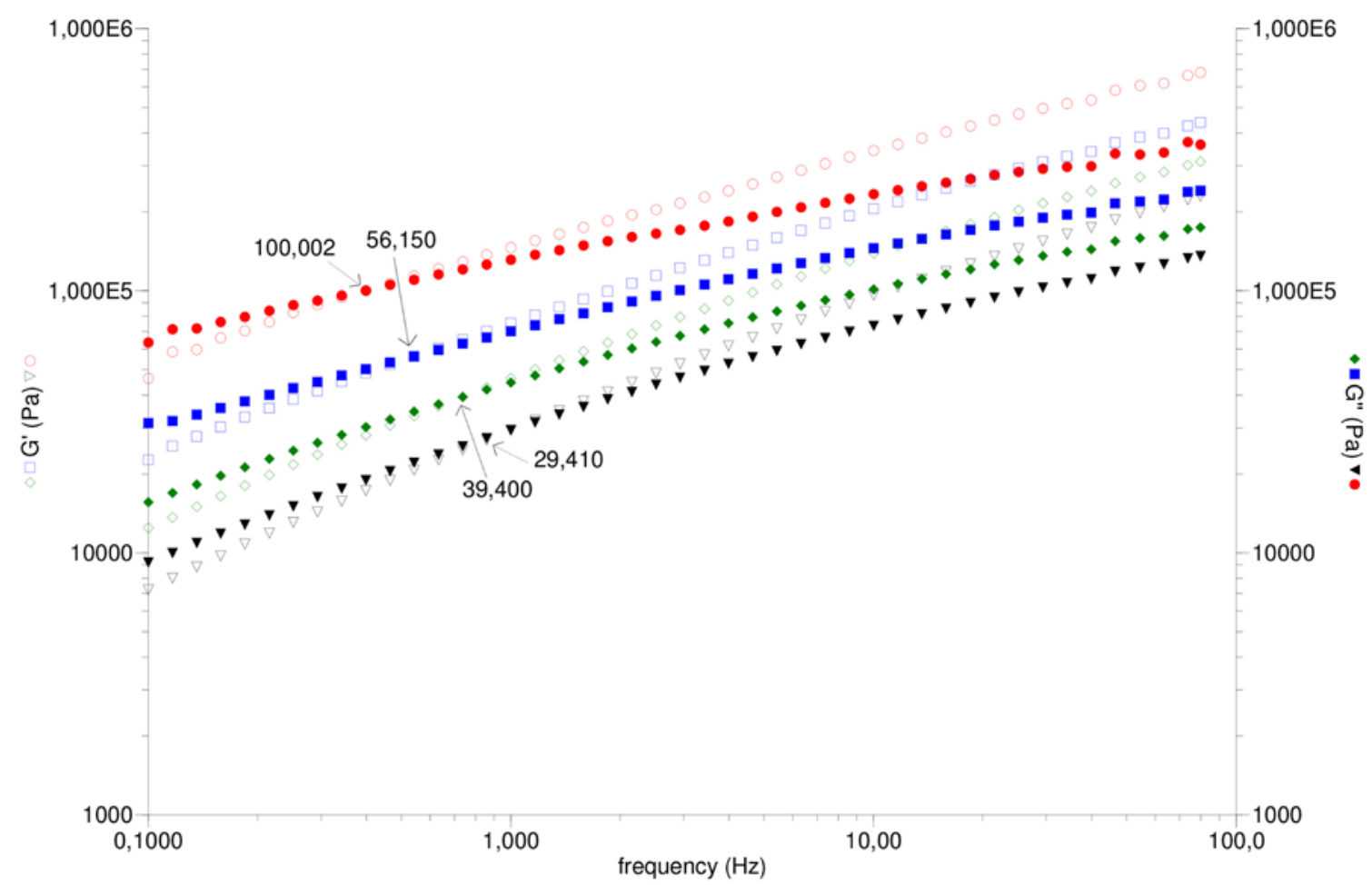

Figure 8. Overlay of the module at the crossover point. 
The overlay of the complex viscosity curves $\left(\eta^{*}\right)$ of the composites (Figure 9) confirms the trends shown by the results of fo curves. The viscosity rose with the increase of SCB content, and decreased with the increase of frequency, showing the pseudoplastic behaviour of the materials. The presence of fibres has changed the average flow of the rHDPE, and restrained the mobility of the molten polymer. The composites became more resistant to deformation than the neat polymer in the melt state. According to Lozano et al. [32], the decrease in viscosity at higher frequencies can be a plus because it means that it will probably not be a problem to process these composites at high shear rates (average processing conditions of polyolefin).

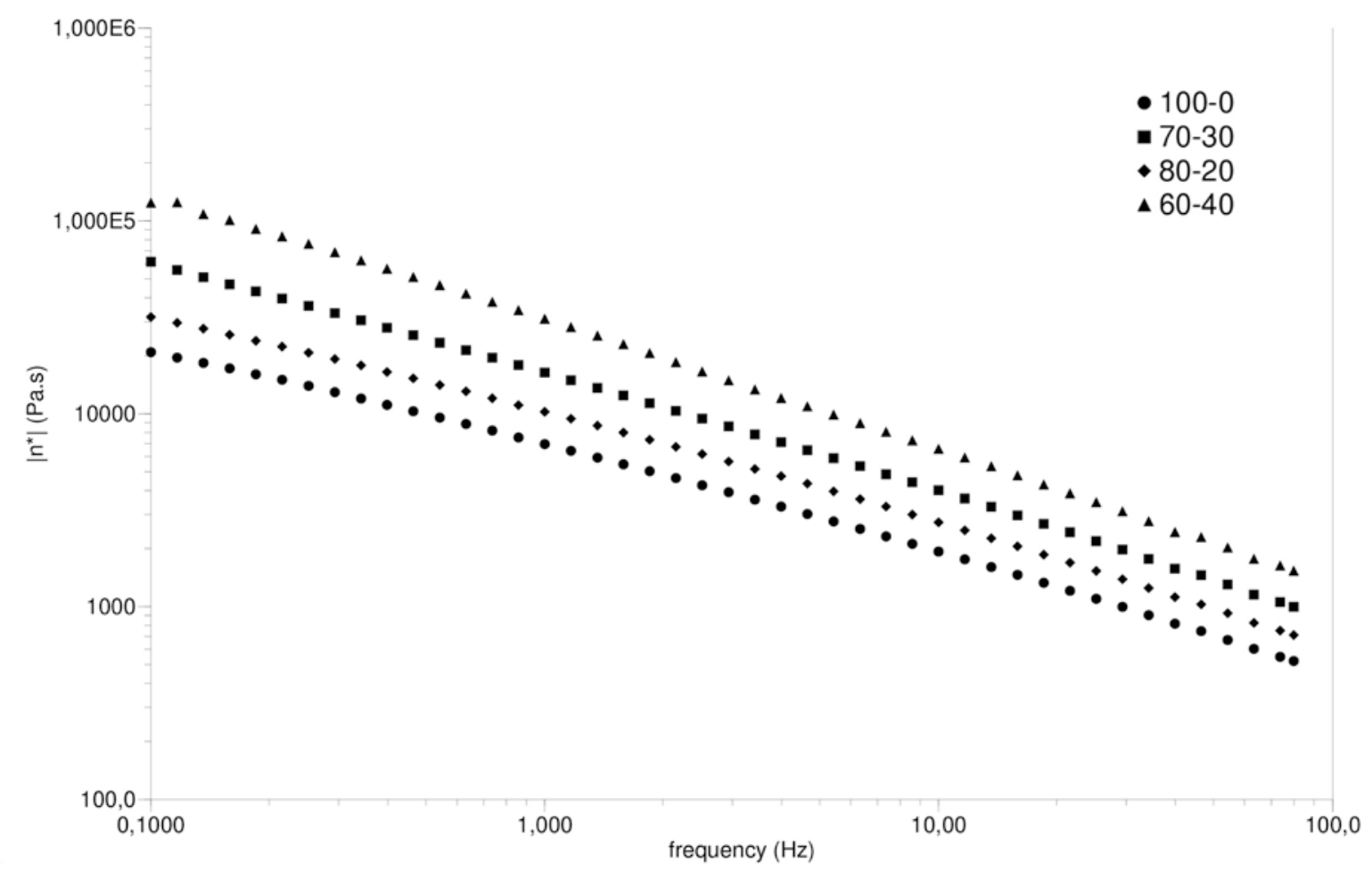

Figure 9. Overlay of the complex viscosity $\left(\eta^{*}\right)$ of the composites.

\section{Conclusions}

Considering the aim of the study-recycling polymeric waste materials to produce building materials-we concluded that SCB has actually improved the compressive strength of the neat rHDPE. There was a good dispersion and adhesion between polymer and filler-shown in the SEM images-probably due to the presence of lignin in the non-treated SCB. This is an important aspect for the resistance to compressive stress and is just a consequence of the choice for not making any chemical treatment on the fibre (in order to avoid the creation of pollutant effluents). Regarding the thermal properties, the TGA showed that the composites could be used to produce average HDPE artefacts, within the usual temperature of neat polymer. The DSC analysis pointed out an increase in the $X_{c}$ of the polymer-related to the transcrystallization furthered by the SCB over regions of uncrystallized polymer in the matrix - which may have reinforced the already strong mechanical properties of this kind of polyolefin. The SCB has actually improved the compressive strength of the neat rHDPE. As the rheological measurements showed no abnormality, the anomalous result of the secant modulus of 70-30 composite could be explained by inhomogeneous compounding and/or injection moulding of this specimen in particular or by measurement/calibration error of the universal testing machine during the compressive strength test of this specimen in particular. 
The rheological measurements showed that the composites were more resistant to deformation than the neat polymer in the melt state, but they would probably be processed at the average processing conditions of HDPE artefacts (high shearing rates). Therefore, we conclude this material has achieved enough properties to be used as a sustainable and easy-to-make building material.

Acknowledgments: The authors thank the Conselho Nacional Desenvolvimento Científico e Tecnológico (CNPq), the Coordenação de Aperfeiçoamento de Pessoal de Nível Superior (CAPES), the undergraduate students Jair B. Gabriel (Materials engineering, UFRJ) and Gabriel C. B. Avila (Chemical engineering, UFRJ) for their work in this research, and to the Nosso Futuro Comum blog community headed by the economist Hugo Penteado (for fostering crowdfunding to buy equipment to our research line) for supporting this research.

Author Contributions: Sibele P. Cestari conceived the study, carried out the lab work, the compounding of the composites, participated in data analysis, carried out thermal analysis, designed the study and drafted the manuscript; Luis C. Mendes participated in the design of the study, coordinated the study, and carried out the correlation amongst results and helped draft the manuscript; Volker Altstädt carried out the injection moulding and the compressive strength test of the cylindrical specimens; Léa M. A. Lopes analysed the data and carried out the rheological measurements. All authors gave final approval for publication.

Conflicts of Interest: The authors declare no conflict of interest.

\section{References}

1. Lima, A.C.; Monteiro, S.N.; Satyanarayana, K.G. Recycled polyethylene composites reinforced with jute fabric from sackcloth: Part i-preparation and preliminary assessment. J. Polym. Environ. 2012, 20, 245-253. [CrossRef]

2. Yu, L.; Dean, K.; Li, L. Polymer blends and composites from renewable resources. Prog. Polym. Sci. 2006, 31, 576-602. [CrossRef]

3. Brown, L.R. Eco-Economy: Building an Economy for the Earth; W.W. Norton \& Company: New York, NY, USA, 2001.

4. Brown, L.R. Plan B 4.0: Mobilizing to Save Civilization (Substantially Revised); W.W. Norton \& Company: New York, NY, USA, 2009.

5. Mohanty, A.; Misra, M.; Drzal, L. Sustainable bio-composites from renewable resources: Opportunities and challenges in the green materials world. J. Polym. Environ. 2002, 10, 19-26. [CrossRef]

6. Solow, R.M. The economics of resources or the resources of economics. Am. Econ. Rev. 1974, 64, 1-14.

7. Martins, A.F.; Suarez, J.C.M.; Mano, E.B. Recycled polyolefin products with higher performance than the corresponding virgin materials. Polímeros 1999, 9, 27-32. [CrossRef]

8. Santi, C.R.; Correa, A.C.; Manrich, S. Films of post-consumer polypropylene composites for the support layer in synthetic paper. Polímeros 2006, 16, 123-128. [CrossRef]

9. Braungart, M. Upcycle to eliminate waste: The chemist recasts materials in an endless loop. Nature 2013, 494, 174-175. [CrossRef]

10. McDonough, W.; Braungart, M.; Clinton, B. The Upcycle: Beyond Sustainability_Designing for Abundance; Macmillan: New York, NY, USA, 2013.

11. Da Silva Hipolito, I.; da Silva Hipolito, R.; de Almeida Lopes, G. Polímeros na construção civil. In Proceedings of the Simpósio de Excelencia em Gestão e Tecnologia, Resende, Brazil, 23-25 October 2013.

12. Antink, R.; Garrigan, C.; Bonetti, M.; Westaway, R. Greening the Supply Chain; DTI/1753/PA; UNEP-SBCI: Paris, France, 2012; p. 88.

13. Lauriano, L.A. Como anda a Gestão da Sustentabilidade no Setor da Construção? Avaiable online: http:/ / acervo.ci.fdc.org.br/AcervoDigital/Relat $\%$ C3\%B3rios\%20de \%20Pesquisa/Relat $\%$ C3\% B3rios\%20de\%20pesquisa\%202013/RP1301.pdf (accessed on 29 April 2016).

14. Roodman, D.M.; Lenssen, N.; Peterson, J.A. A Building Revolution: How Ecology and Health Concerns are Transforming Construction; Worldwatch Institute: Washington, DC, USA, 1995.

15. Conroy, A.; Halliwell, S.; Reynolds, T. Composite recycling in the construction industry. Compos. A Appl. Sci. Manuf. 2006, 37, 1216-1222. [CrossRef]

16. Piva, A.M.; Wiebeck, H. Reciclagem do Plástico: Como Fazer da Reciclagem um Negócio Lucrativo; Artliber: São Paulo, Brazil, 2004; p. 111.

17. Mendes, L.C.; Cestari, S.P. Printability of HDPE/natural fiber composites with high content of cellulosic industrial waste. Mater. Sci. Appl. 2011, 2, 1331-1339. [CrossRef] 
18. Cestari, S.P.; Mendes, L.C. Thermal properties and morphology of high-density polyethylene filled with coffee dregs. J. Therm. Anal. Calorim. 2013, 114, 1-4.

19. Cestari, S.P.; Mendes, L.C.; Altstadt, V.; Mano, E.B.; Silva, D.F.D.; Keller, J.-H. Crystallization kinetics of recycled high density polyethylene and coffee dregs composites. Polym. Polym. Compos. 2014, 22, 541-550.

20. Cestari, S.P.; Mendes, L.C.; Silva, D.F.D.; Chimanowsky, J.P., Jr.; Altstädt, V.; Demchuk, V.; Lang, A.; Leonhardt, R.G.; Keller, J.-H. Properties of recycled high density polyethylene and coffee dregs composites. Polimeros 2013, 23, 733-737. [CrossRef]

21. Bozorg-Haddad, A.; Iskander, M.; Chen, Y. Compressive strength and creep of recycled HDPE used to manufacture polymeric piling. Constr. Build. Mater. 2012, 26, 505-515. [CrossRef]

22. ASTM-D695. D695. In Standard Test Method for Compressive Properties of Rigid Plastics; American Society for Testing and Materials: Philadelphia, PA, USA, 2010.

23. Acha, B.; Marcovich, N.; Reboredo, M. Lignin in jute fabric-polypropylene composites. J. Appl. Polym. Sci. 2009, 113, 1480-1487. [CrossRef]

24. Redighieri, K.I.; Costa, D.A. Propriedades mecânicas e absorção de água dos compósitos de pebdrec e partículas de madeira de reflorestamento. Rev. Univ. Rural Sér. Ciênc. Exatas Terra 2006, 25, 28-35.

25. Pandey, A.; Soccol, C.R.; Nigam, P.; Soccol, V.T. Biotechnological potential of agro-industrial residues. I: Sugarcane bagasse. Bioresour. Technol. 2000, 74, 69-80. [CrossRef]

26. Guimarães, J.; Frollini, E.; Da Silva, C.; Wypych, F.; Satyanarayana, K. Characterization of banana, sugarcane bagasse and sponge gourd fibers of brazil. Ind. Crops Prod. 2009, 30, 407-415. [CrossRef]

27. Ramos, F.; Mendes, L. Recycled high-density polyethylene/gypsum composites: Evaluation of the microscopic, thermal, flammability, and mechanical properties. Green Chem. Lett. Rev. 2014, 7, 199-208. [CrossRef]

28. Apostolov, A.A.; Evstatiev, M.; Denchev, Z.; Friedrich, K.; Fakirov, S. Effect of composition on transcrystallization with reorientation of polypropylene in drawn PET/PP blend. J. Mater. Sci. 2007, 42, 1245-1250. [CrossRef]

29. Na, B.; Guo, M.; Yang, J.; Tan, H.; Zhang, Q.; Fu, Q. Crystal morphology and transcrystallization mechanism of isotactic polypropylene induced by fibres: Interface nucleation versus bulk nucleation. Polym. Int. 2006, 55, 441-448. [CrossRef]

30. NBR-6136. Blocos Vazados de Concreto Simples para Alvenaria-Requisitos. Avaiable online: http://www. construpac.com.br/pdf/nbr6136.pdf (accessed on 29 April 2016).

31. Kealy, T. Rheological analysis of the degradation of HDPE during consecutive processing steps and for different processing conditions. J. Appl. Polym. Sci. 2009, 112, 639-648. [CrossRef]

32. Lozano, K.; Yang, S.; Zeng, Q. Rheological analysis of vapor-Grown carbon nanofiber-Reinforced polyethylene composites. J. Appl. Polym. Sci. 2004, 93, 155-162. [CrossRef] 